\title{
Research programs of the AOA and their role in osteopathic education
}

\author{
KONRAD C. RETZ, PhD
}

The research programs of the AOA Bureau of Research (Bureau) have had a long history. ${ }^{1,2}$ The chief goal of these programs has been to investigate problems of a biologic nature in order to obtain a better understanding and a more effective application of the philosophy and concepts of osteopathic medicine. With the 1986 mandate from the AOA Board of Trustees to develop research training in osteopathic residencies, efforts have begun to focus on the role that research experiences can and should play in osteopathic medical education. This report focuses on the current priorities of the Bureau and the many current research activities of the AOA (Table).

\section{Administration of research supported by the AOA}

\section{Bureau of Research}

The Bureau of Research began as the Committee on Research in 1939. In 1943, the Osteopathic Research Council, an advisory board, was established. This latter group had its name changed to the Osteopathic Research Board in 1945. In 1951, the Committee on Research became the Bureau of Research and was merged with the Osteopathic Research Board. In 1986, the Bureau was reorganized into its present form.

The Bureau's charge is to encourage scientific research and to maintain and improve high standards of medical education in osteopathic colleges as mandated by "Article IIObjectives" of the AOA Constitution. The Bureau represents the Board of Trustees in promoting and enhancing the research programs of the AOA, of the osteopathic profession in

Dr Retz is assistant director, Division of Research and Predoctoral Education, AOA Department of Education.

Reprint requests to Konrad C. Retz, PhD, AOA Department of Education, 142 East Ontario St, Chicago, IL 60611-2864. general, and its affiliated organizations and institutions. Therefore, the Bureau is responsible for the growth and development of the osteopathic research program of the profession, and for providing assurance of a consistently high standard in research supported by the AOA. The Bureau is chaired by a member of the Board of Trustees and is composed of nine members selected to represent the diverse interests of the practice and nonpractice affiliates of the AOA. (See Appendix I, page 1034.)

The work of the Bureau itself is accomplished through its meetings in the spring and fall of each year. Because of the diverse operations needed to create and maintain biomedical and clinical research programs of high quality, the Bureau has recently witnessed the creation of three standing committees (Figure), whose scope and function are described below. With the creation of these committees, the Bureau has been able to devote more time to policy matters as the committees have undertaken the primary role in initial evaluation and administration of selected research programs. The AOA research grant and fellowship programs are fully described in the $O s$ teopathic Research Handbook, ${ }^{3}$ published in September of each year. This handbook is widely distributed and may be obtained from the AOA Department of Education, Division of Research and Predoctoral Education.

\section{Committee on Funding for Research and Education}

In 1986, the Board of Trustees approved the establishment of the Committee on Research Funding to identify and develop additional sources of funding for the AOA research programs. With the realization that funding of research and funding of research training programs are frequently intertwined, in 1989 , the Board approved the renaming of this committee to its present name. 
Table

Current Research and Awards Programs Managed by the American Osteopathic Association

Research programs

A.T. Still Foundation and Research Institute

AOA Research Grants

Burroughs Wellcome Fellowships

Annual Research Conference

\section{Awards}

Gutensohn/Denslow Award

Louisa Burns Memorial Lectureship

Burnett Osteopathic Student Research Award

Marion Merrell Dow Research Conference Student Award

The committee's current charge is to evaluate and carry out AOA policy on the design and implementation of programs to secure funds for AOA research and education activities that are under the supervision of the $\mathrm{Bu}$ reau. The committee comprises four to ten voting members, of whom three must be osteopathic physicians (See Appendix I, page 1034.) In addition to staff support from the AOA Department of Education, this committee also receives staff support from the AOA Controller. Consultation is provided to the Committee through the AOA General Counsel and others as necessary.

One of the newest sources of funding that this committee will be responsible for developing is the "Fund for Osteopathic Research and Education." The Bureau, with the support of the AOA Board of Trustees, has undertaken a capital campaign to develop a new source of monies for research. This fund is administered by the Bureau under guidelines published in the Osteopathic Research Handbook. As the principal of the fund grows, earned income thereof will become available to fund long-range programs, including research grants and fellowships, manpower development and education programs, and research resources development.

\section{Committee on Research Conferences}

The present Committee on Research Conferences was established as the Committee on the Research Conference by the Board of Trustees in 1986 to assist the Bureau in implementing AOA policy as relates to the AOA Annual Research Conference. In 1990, the Board enlarged the Committee's role to include all re- search conferences and workshops of the Bureau. The Committee is composed of up to six voting members and is chaired by a member of the Bureau. (see Appendix I, page 1034.)

\section{Committee on Research Grants}

The Committee on Research Grants was established by the Board of Trustees in 1986 to implement AOA policy on the evaluation and funding of research projects. More specifically, this committee is charged with processing grant applications, evaluating their worthiness, presenting funding recommendations to the Bureau, and monitoring the status of research supported by the AOA by receiving reports from grantees. This committee comprises six voting members who all have grant reviewing expertise. (See Appendix I, page 1034.)

\section{AOA Department of Education}

Administrative support for the Bureau and its three Committees is provided by the offices of the Director of the AOA Department of Education and of the Assistant Director, Division of Research and Education. In addition to secretarial services, the Division also administers the AOA Grants, A. T. Still Foundation and Research Institute Grants, and Burroughs Wellcome Fellowships, AOA Annual Research Conference, Marion Merrell Dow Research Conference Student Award, and special award programs of the Bureau.

\section{National Osteopathic Foundation}

The National Osteopathic Foundation (NOF) is a separately incorporated organization affiliated with the AOA. It serves the osteopathic profession through philanthropic activities and efforts. One goal of the NOF is to support research through liaison with the Bureau. For example, the NOF is one interface between potential corporate sponsors of research programs of the Bureau and the Bureau membership. Certain monies raised through NOF are distributed by the Bureau for approved research programs.

\section{National Association of Osteopathic Foundations}

The National Association of Osteopathic Foun- 


\section{AOA Board of Trustees}

AOA policies and budgets

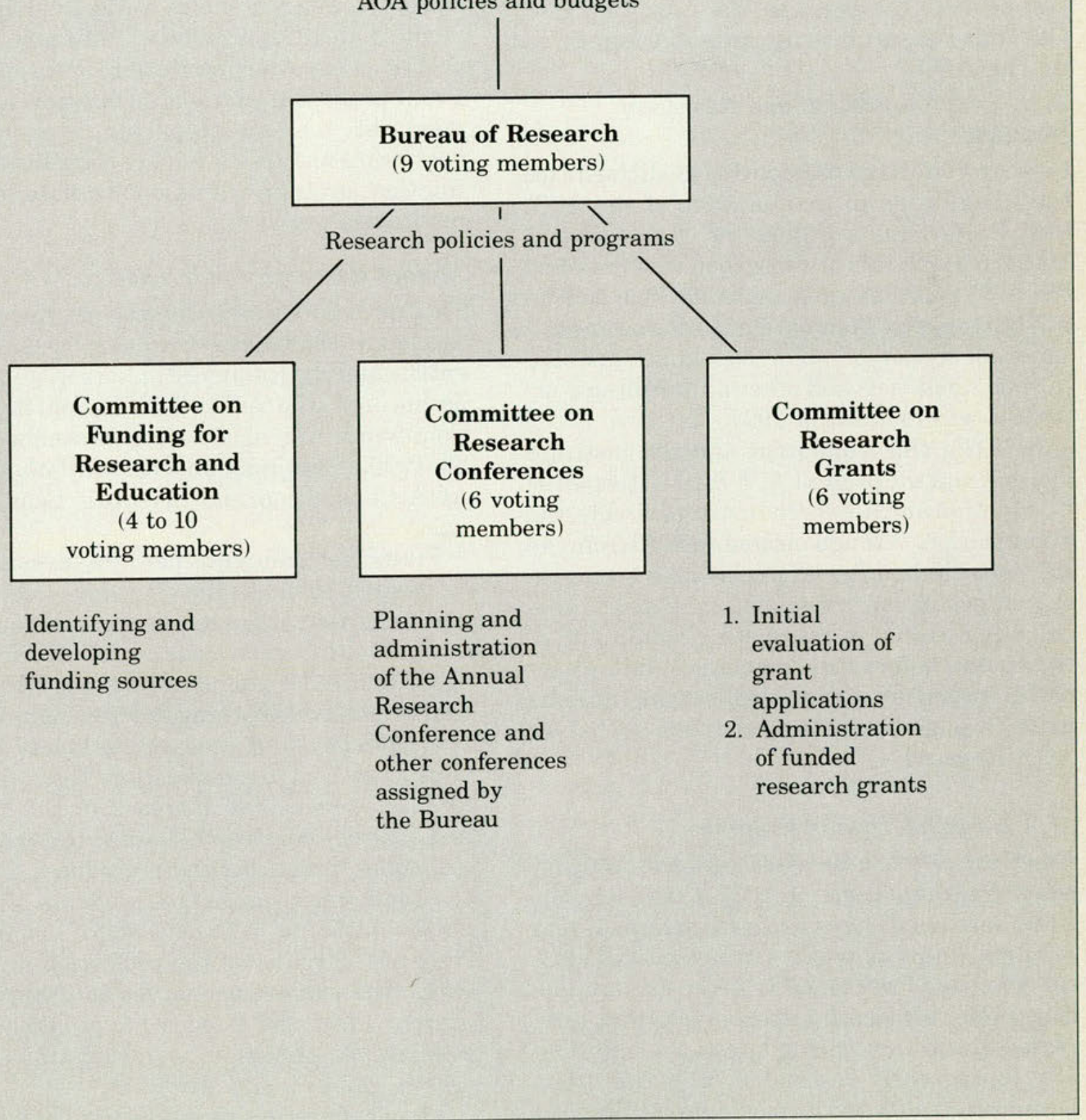

Figure. Mechanism of administration of research supported by the AOA. 
dations (NAOF) is an organization of independent and AOA-affiliated osteopathic foundations. The objectives of this organization serve to improve the effectiveness of each member group by providing advice, counsel, and expertise in several areas, including foundation management, funding resources, grant proposal development, public relations, marketing, and evaluating fund-raising needs of each group member. Liaison is maintained between the NAOF and the Committee on Funding for Research and Education.

\section{Current research programs managed by the AOA}

\section{A. T. Still Foundation and Research Institute}

Research efforts in osteopathic medicine trace their beginning to the founding of the A. T. Still Postgraduate College of Osteopathy in 1907. In 1909, this organization was renamed the A. T. Still Research Institute. The American Osteopathic Foundation, a related organization for support of research, publications, educational facilities, and other philanthropic activities was founded in 1927.

In 1935 , the foundation and the institute merged into the present A. T. Still Osteopathic Foundation and Research Institute. Today, the organization, through income derived from the Burnett-Timken Trust fund, awards 1-year research grants for investigations that are specifically directed to osteopathic manipulative treatment, osteopathic principles, and osteopathic practices. Grant applications may be made through the same mechanism as that for AOA Research Grants.

\section{AOA Research Grants Program}

American Osteopathic Association funding for research grants began in 1937. Currently, the AOA Research Grants Program awards 1-year research grants for projects in biologic and clinical sciences. Preference is given to research done under osteopathic sponsorship that is directed toward answering questions traditionally or currently associated with the osteopathic profession and its particular philosophy or practice.
Funds for AOA research grants are awarded only to institutions meeting the requirements for general assurances, use of budgeted equipment, and protection of research subjects. The principal investigator of an application for funding from AOA research programs must be: (a) an osteopathic physician who holds a fulltime appointment at an AOA-accredited, affiliated, or approved osteopathic institution; or (b) a biomedical researcher who demonstrates evidence of professional training and experience as appropriate for his or her individual discipline and who holds a full-time appointment at an AOA-accredited, affiliated, or approved osteopathic institution; or (c) an osteopathic physician, who holds a full-time appointment at a nonosteopathic academic or healthcare institution having accreditation, affiliation, or approval as appropriate for that institution's activities.

\section{Annual Research Conference}

The Annual Research Conference, since its inception in 1955, has served as a forum for scientists and clinical investigators within osteopathic institutions. The 34th Annual Research Conference was held during November 25 to 29, 1990, in conjunction with the 95th Annual AOA Convention and Scientific Seminar in Las Vegas, Nev.

First, the conference permits investigators to present their findings to their colleagues and to participate in discussion and constructive criticism. Second, the conference provides opportunities for attendees to discuss their mutual interests concerning funding, administrative policies, and research interest topics, which may lead to collaboration. Third, the conference promotes an increase in the quality and quantity of research devoted to osteopathic principles, practices, and procedures. Fourth, the conference encourages students of osteopathic medicine to become more involved in research activities of the profession. In these ways, the conference serves to promote research within the osteopathic profession and to allow the profession to demonstrate its research interests and strengths.

The conference's program has centered on general scientific sessions, including both 
poster and slide formats. Symposium and forum sessions of the program provide appeal to both $\mathrm{PhD}$ and $\mathrm{DO}$ scientists through the inclusion of topics addressing issues of importance to both groups. This process has been an ongoing one and will be further strengthened by continued association of the conference with the AOA Annual Convention. The programming of the conference undergoes continuous evaluation in order to be responsive to the growing research needs of the osteopathic profession.

\section{Special awards presented at the Research Conference \\ Burroughs Wellcome Fellowships}

The Burroughs Wellcome Osteopathic Research Fellowship is sponsored by the National Osteopathic Foundation and is funded through the Burroughs Wellcome Company. It is designed to enable the applicant to conduct a basic science or clinical research project that will make a significant contribution to osteopathic medicine. The fellowship is, in effect, "seed" funding to encourage an osteopathic physician to contribute to research throughout his or her career in osteopathic medicine.

The fellowship involves the completion of a project under supervision of a sponsor. The sponsor is usually an established investigator who agrees to furnish support for direct research costs incurred by the fellow. The award is for $\$ 5,000$, consisting of a $\$ 4,250$ stipend and a $\$ 750$ travel allowance to attend the annual AOA Research Conference following the year of the fellowship. In addition, Burroughs Wellcome provides a recognition dinner during the Research Conference for fellowship recipients and their guests, sponsors and their guests, and representatives of the Burroughs Wellcome staff, NOF staff, and AOA officers and staff.

\section{Gutensohn/Denslow Award}

The Gutensohn/Denslow Award is sponsored by the AOA Bureau of Research and the National Osteopathic Foundation. This award is given in honor of J. S. Denslow, DO, a noted researcher in viscerosomatic reflexes and biomechanics, and in honor of Max T. Guten- sohn, DO, a noted educator and past chairman of the Bureau of Research. Nominees must be either an osteopathic physician or hold a doctoral level degree and be on the faculty or staff of an osteopathic institution. They must be, or have been, actively involved in clinical or basic science research as well as the education process. The $\$ 5,000$ award is funded by the Burroughs Wellcome Company. Previous Laureates are: Albert F. Kelso, PhD (1984); Wilbur V. Cole, DO (1985); Irvin M. Korr, PhD (1987); Myron C. Beal, DO (1988); Robert W. Gracy, PhD (1989); and Richard J. Cenedella, $\mathrm{PhD}$ (1990).

\section{Louisa Burns Memorial Lectureship}

The Louisa Burns Lectureship is named in honor of Louisa Burns, DO, who headed the A. T. Still Research Institute from 1914 to 1936. With her graduation from the Pacific College of Osteopathy, San Francisco, in 1903, Dr Burns was the first individual in the osteopathic profession to establish a long-term research program. This award was initiated in 1969 , and its recipient is recognized annually with the delivery of the Louisa Burns Memorial Lecture at the AOA Research Conference.

\section{Burnett Osteopathic Student Research Award}

The Bureau of Research offers the annual Burnett Osteopathic Student Research Award. Recognizing a student of osteopathic medicine for the most outstanding concept paper pertaining to an osteopathic-oriented research proposal, the award consists of an all-expense paid trip to the annual Research Conference plus $\$ 100$ cash. The award is named in honor of the contributions made to the osteopathic profession by John H. Burnett, DO, and Mary M. Burnett, DO. Support for the award has been provided by interest earned from the Burnett Presidential Award. Eligibility is limited to students enrolled in AOA-accredited colleges of osteopathic medicine.

\section{The role of research in osteopathic medical education}

As osteopathic medicine prepares to enter its second century, several exciting research prob- 
lems remain to be addressed. In order to be prepared for this challenge, the profession needs to develop more researchers from within its ranks. To facilitate that process, it is important that predoctoral and postdoctoral osteopathic students see successful role models actively pursuing their career paths. Early exposure to researchers, be they biomedical investigators ("basic scientists") or osteopathic physicians engaged in clinical investigation, is often the seminal event in one's decision to consider a career as a researcher. The Research Conference will continue to play a major role in this process.

The expanding operations of the Bureau will provide more opportunities for osteopathic physicians to become involved with research. One program now under consideration would be specifically targeted toward identifying and training younger osteopathic physicians for careers in research. With the identification and development of larger sources of funding, it should be possible to fund more long-term projects. One such example has been the Low Back Pain Study conducted at Michigan State University-College of Osteopathic Medicine. That study was made possible by funds from the Quad Cities Osteopathic Foundation and the Northwest Osteopathic Medical Foundation.

As a first step toward obtaining new funding capabilities, the AOA membership has elected to develop the Fund for Osteopathic Research and Education. With the growth of this fund to its projected $\$ 5,000,000$ principal by the year 2000 , the AOA will be assured of having the ability to provide seed or matching funds (or both) for larger long-term projects.

1. 1990 Yearbook and Directory of Osteopathic Physicians, ed 81. Chicago, American Osteopathic Association, 1990.

2. Northup GW: Osteopathic Research: Growth and Development. Chicago, American Osteopathic Association, 1987.

3. Osteopathic Research Handbook.Chicago, American Osteopathic Association, 1989. 